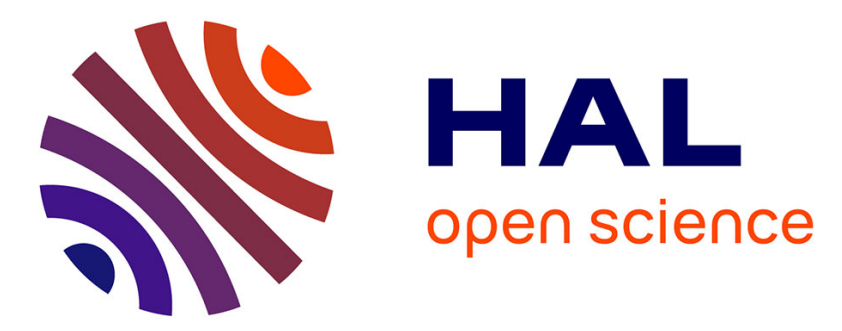

\title{
Mechanical study of a support system for cupping control of panel paintings combining crossbars and springs
}

Bertrand Marcon, Paola Mazzanti, Luca Uzielli, Linda Cocchi, David Dureisseix, Joseph Gril

\section{To cite this version:}

Bertrand Marcon, Paola Mazzanti, Luca Uzielli, Linda Cocchi, David Dureisseix, et al.. Mechanical study of a support system for cupping control of panel paintings combining crossbars and springs. Journal of Cultural Heritage, 2012, 13 (53), pp.5109-5117. 10.1016/j.culher.2012.04.003 . hal-00703650

\section{HAL Id: hal-00703650 https://hal.science/hal-00703650}

Submitted on 4 Jun 2012

HAL is a multi-disciplinary open access archive for the deposit and dissemination of scientific research documents, whether they are published or not. The documents may come from teaching and research institutions in France or abroad, or from public or private research centers.
L'archive ouverte pluridisciplinaire HAL, est destinée au dépôt et à la diffusion de documents scientifiques de niveau recherche, publiés ou non, émanant des établissements d'enseignement et de recherche français ou étrangers, des laboratoires publics ou privés. 


\title{
Mechanical study of a support system for cupping control of panel paintings combining crossbars and springs
}

\author{
B. Marcon ${ }^{1,2,3,}{ }^{*}$, P. Mazzanti ${ }^{1}$, L. Uzielli ${ }^{1}$, L. Cocchi $^{1}$, D. Dureisseix ${ }^{4}$, J. Gril $^{2}$
}

1 DEISTAF, University of Florence,Italy paola.mazzanti@unifi.it , luca.uzielli@unifi.it , linda.cocchi@gmail.com

${ }^{2}$ Laboratoire de Mécanique et Génie Civil (LMGC), CNRS UMR 5508 Université Montpellier 2, France joseph.gril@univ-montp2.fr

${ }^{3}$ Research Institute for sustainable humanosphere (RISH), University of Kyōto, Japan bertrand_marcon@rish.kyoto-u.ac.jp

${ }^{4}$ Laboratoire de Mécanique des Contacts et des Structures (LaMCoS), CNRS UMR 5259 Université de Lyon 1, France / INSA de Lyon, VILLEURBANNE, France David.Dureisseix@insa-lyon.fr

\begin{abstract}
Spring mechanisms have been developed, since late 1970s, to provide some freedom of deformation to the wooden supports of paintings; however, no scientific method is up to now available for optimizing their design parameters. This article deals with theoretical and experimental work on the replica of an actual wooden support restored in a Florentine laboratory. A model is developed to describe its deformational behaviour after an auxiliary support has been applied by means of springs. The main outcome of such a research, still on-going, is a numerical model verified experimentally, enabling a restorer to choose the most appropriate mechanical parameters for springs in order to obtain the desired control of deformations and stresses produced by the expected environmental conditions.
\end{abstract}

Keywords: panel paintings; wood structures; finite elements; moisture-induced stress; conservation; cultural heritage

\section{Research aims}

To design a spring-controlled support system for conservation of panel paintings, a numerical model is useful to predict the behaviour of both the board and the support in response to variations of environmental conditions. This article presents a practical model, as simplified as possible but sufficient to take into account the main phenomena and to allow the choice of the design parameters to obtain a given control of the mechanical behaviour of the wooden support. 


\section{Introduction}

Interventions that contribute to long-term conservation of panel paintings in the best possible state have presented a challenge to curators and restorers. Variation of environmental microclimate may induce changes in moisture content and moisture gradients, transient or permanent deformations, stresses and damage to both the wooden support and the paint layer, up to the detachment of the layer from the wooden support [1]. Wood science, specifically using modelling of phenomena like shrinkage/swelling, creep, relaxation, and mechano-sorptive effects, can help to analyse and optimize restoration interventions [2-7], taking into account the individual painted panels and their environment including the contribution of ground layers, paint layers and protective varnishes. Crossbeams or more complex frameworks were often applied on the back face of a support, having - among others - the function of controlling its deformations produced by fluctuations of the environmental conditions (especially air temperature and relative humidity). Connections between the boards and the cross-beams are of various types, including nails (clinched back into the wood to prevent them from slipping off), metal or wooden bridges or other devices allowing for some sliding, dovetailed couplings (trapezoidal shape of the cross-beam's cross-section, inserted in corresponding grooves made in the planking; however, sliding is not so easy due to the large friction forces acting on the slanted edges). Although the above connections were designed to allow for some movements and to minimize damage, they cannot cope with large environmental variations taking place, for example, in "difficult" original locations or when paintings are moved from original locations to museums where heating systems are installed, or when the presence of a large number of visitors severely modifies the environment. Many interventions have been devised and implemented to modify the mechanical characteristics of the connection between planking and crossbeams, and hence to reduce damage, for instance see [2]. Although based on good intentions, many of such interventions have had negative consequences. At present time, the soundest approach to solving the problems is to control the environmental conditions (if possible) rather than to modify the physical structure of the wooden support. However, in many cases, there is a need for replacing or reconstructing the system of crossbeams; e.g. when it has been destroyed by previous interventions, or when serious accidents have severely damaged the support.

In these cases, a compromise needs to be reached: a stiff connection will induce permanent deformations (caused by complex rheological phenomena in wood) and, in case of large environmental variations, it may even produce cracks and ruptures in the wooden support and, in consequence, damages to the paint layer; whereas a too yielding connection will be useless, being unable at all to control deformations. An interesting supporting technique was developed since 1987 at OPD (Opificio delle Pietre Dure - a state restoration laboratory located in Florence, Italy) consisting of a supporting system, connected to the rear of the panel by means of springs (Fig. 1). This kind of structure is described by Ciatti [8], Uzielli [9] and Miller [10]. 


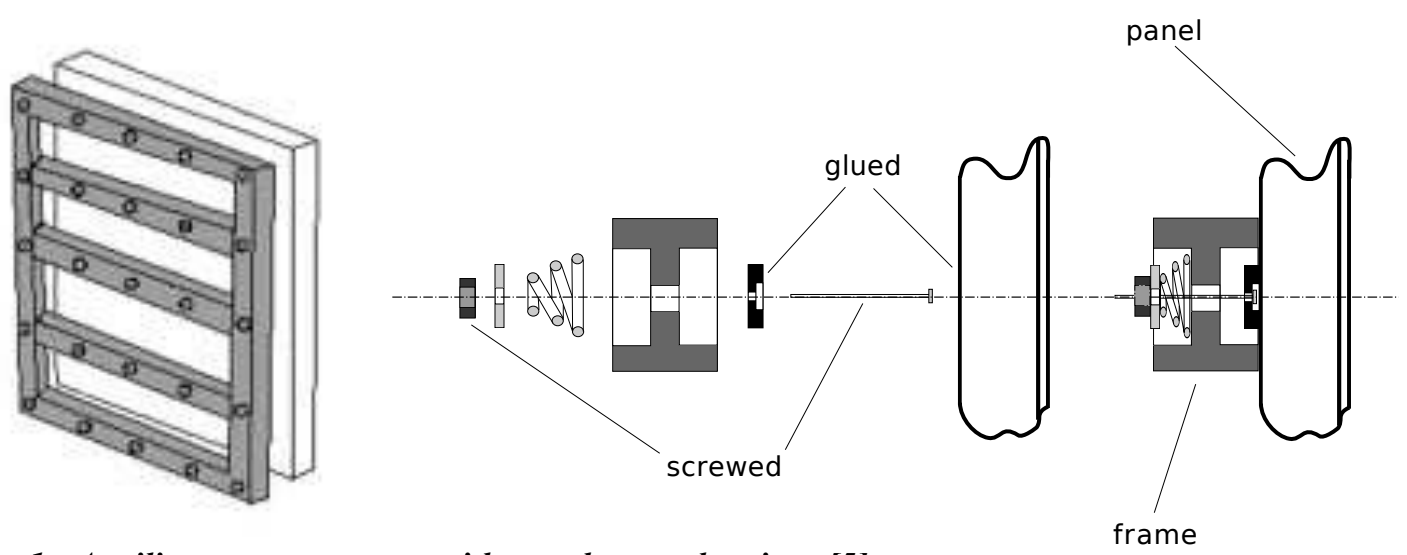

Fig. 1 - Auxiliary support system with crossbars and springs [5]

The practical implementation of such a technique is quite satisfactory, and has now been adopted by several restoration laboratories; however, one of the main problems still unsolved, is the definition of the most desirable mechanical parameters of the springs, i.e. their stiffness and the pre-load to be used when installing them. Of course, such parameters cannot be the same in every case, but need to be calibrated for each situation. In fact, the question implies two aspects: (a) choosing the type and amount of desirable control, to obtain the best possible conservation of the painting; this fundamental choice, to be made on the basis of the conservation problems shown by the painted panel, and of the expected environmental conditions, is not discussed in this paper; (b) choosing the mechanical parameters of springs to obtain the desired mechanical behaviour of the panel, is discussed in this paper. To illustrate the approach, a specific situation and set of assumptions will also be considered.

\section{Experiment}

\subsection{Experimental set-up and testing}

The experimental set-up consists of two partial replicas (i.e. two sections of planking made of "new" wood, having the same thickness and width of the original, of reduced length along the grain direction, one of them similarly connected with springs to an equivalent frame as the original) of an actual panel painting, on which the restorer actually applied a support system similarly connected with springs. The original panel is a Florentine triptych Madonna in trono col Bambino e Santi (Fig. 2), painted in 1435 by Andrea di Giusto $(\sim 1400$ - 1450), conserved at the Museo delle Pitture Murali, Prato, Italy. The painting was restored in 2009 and the auxiliary support with a spring mechanism designed by the Florentine restorer Daniele Piacenti was applied. The wooden support of this triptych, like the supports of many Italian panel paintings, especially in Central Italy during late 13th, 14th and early 15th centuries, was made of boards of poplar (Populus alba L.) [9, 11], glued along their edges to form the planking. For this species, air-dry density $\rho_{o}$ ranges between 390 and 460 kg.m-3 $[6,12]$. 

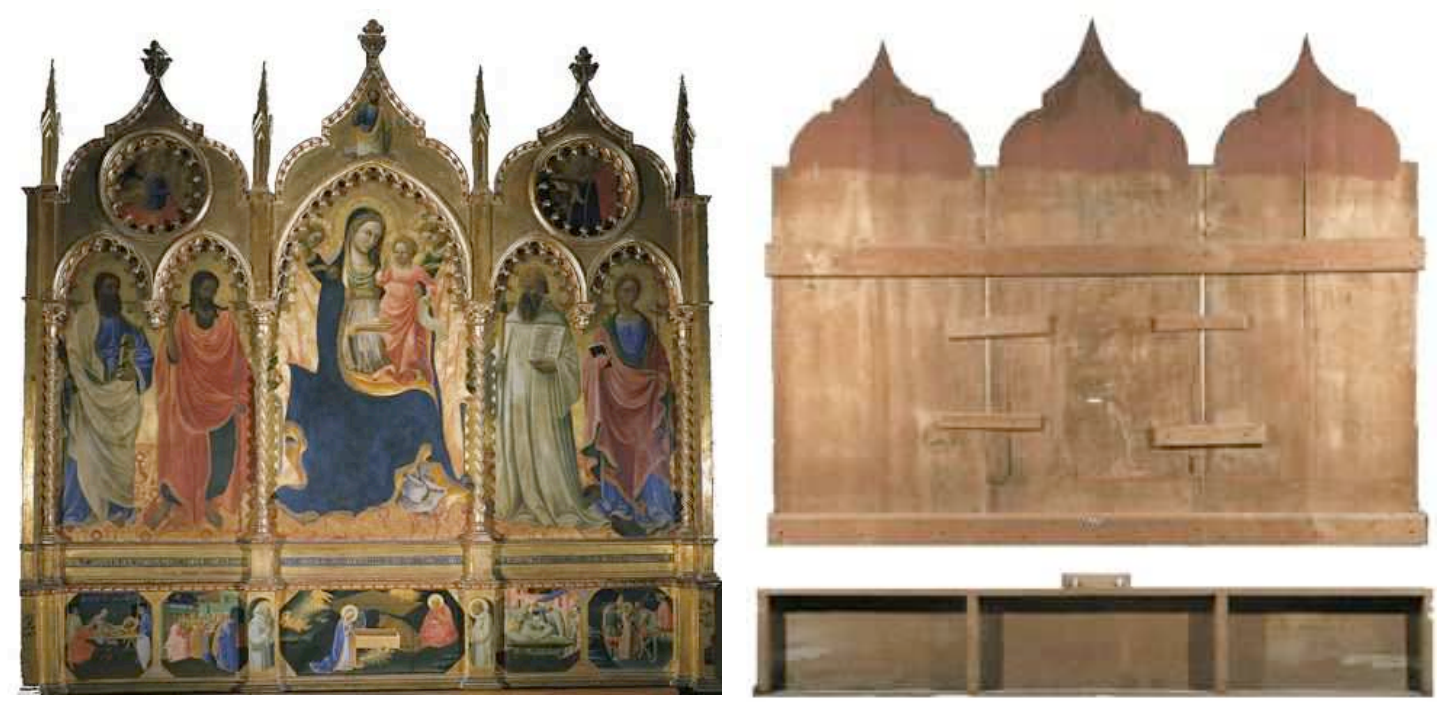

Fig. 2 - Florentine triptych Madonna in trono col Bambino e Santi (1435) by Andrea di Giusto

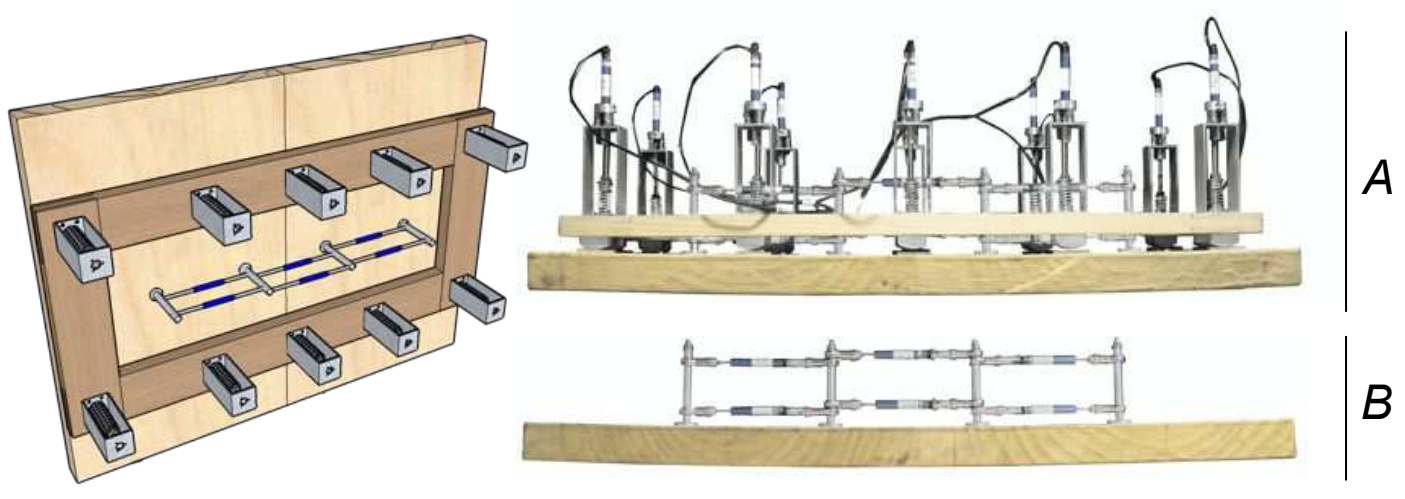

Fig. 3 - Two replicas of a portion of the Triptych, with auxiliary support (A) and without (B); the use of displacement transducers for monitoring curvatures and spring forces is also shown. Note: in order to facilitate reader's understanding of the monitoring system, some connection cables have been removed from the pictures, by retouching them.

Two identical replicas of a portion of the above mentioned panel were built and equipped with measuring devices in order to provide experimental data to be compared with the outcome from the numerical model. Each replica (Fig. 3) was made of two poplar boards glued along an edge; the width $(768 \mathrm{~mm})$ and thickness $(38 \mathrm{~mm})$ were the same as those of the original central panel, whereas the length along the grain was only $600 \mathrm{~mm}$, as compared to the approximately $1200 \mathrm{~mm}$ height of the original panel. The replicas were vapour-proofed with rubber latex on the front face, simulating a protective varnish, as well as on the four lateral edges to eliminate edge effects. Replica "A" was connected by means of springs to an auxiliary support and equipped with 3 "deformometric kits" (DK) [4,7,13-16] to monitor the deformation (cupping and swelling/shrinkage) over time. Additionally, each spring was also equipped with a displacement transducer to monitor its deflection, and hence the force between the panel and the support acting on it. Replica "B" was left free and equipped with 3 DKs. Moreover, the shrinkage/swelling at several points on the back face of both panels were manually measured at time intervals, by means of a digital calliper (resolution $0.01 \mathrm{~mm}$, accuracy $0.05 \mathrm{~mm}$ ). All the sensors were connected to data loggers, so enabling to monitor over time how each panel reacts to humidity 
changes and to evaluate the influence of the auxiliary support. These experimental results are used to assess the numerical model.

The auxiliary support was basically the same as the one installed by the restorer on the original triptych. However, since the panel's length was smaller, the support installed behind replica " $\mathrm{A}$ " included only two cross-beams, connected to each other by two vertical elements to form a rectangular frame; each beam was made of oak wood, $80 \times 22 \mathrm{~mm}^{2}$ cross section, and was connected to the wooden panel by means of 5 equally spaced springs, having stiffness $\kappa=2.4 \mathrm{~N} . \mathrm{mm}^{2}$ and an initial pre-load deformation $v$ of $10 \mathrm{~mm}$, when the panel was still flat.

The two replicas were manufactured and assembled when the wood had reached equilibrium in a climatic chamber set at $30{ }^{\circ} \mathrm{C}$ and $40 \%$ relative humidity $(\mathrm{RH})$. The chamber's climate was then set and maintained at $30{ }^{\circ} \mathrm{C}$ and $80 \% \mathrm{RH}$ during approximately 2 months; during such period equilibrium was not reached. Finally, the chamber's climate was brought back and maintained at $30{ }^{\circ} \mathrm{C}$ and $40 \% \mathrm{RH}$ during almost 7 months; according to graph in Fig. 4, such a long duration was required to reach asymptotically an equilibrium condition. The deformations were automatically monitored by means of the data loggers, performing readings at 15 min intervals, and occasional manual measurements were also performed with the digital calliper. The panels were periodically weighed to assess the changes of their moisture content - the connected equipment was not hygroscopic, therefore its weight remained constant and was considered as an inert tare. Some other pieces from the same original poplar boards were also periodically weighed and eventually oven-dried, so that, based on their oven-dry weight, the wood moisture content at time of each weighing could be calculated.

\subsection{Deflection kinetics in response to humidity changes}

The panel needs almost 5 months to recover a flat state at a stable RH, corresponding to a constant moisture content (MC) through the thickness. Fig. 4 shows that even if the $\mathrm{RH}$ is not perfectly stable, practically the panel does not react to very short perturbations*.

\footnotetext{
* During the initial period at $80 \% \mathrm{RH}$, significant $(\sim 3 \%$ to $10 \% \mathrm{RH})$ fluctuations take place, and the panel reacts with clearly visible deformations (corresponding to approximately $\varepsilon=0.01 \%$ on the back face). During the following period at $40 \% \mathrm{RH}$, fluctuations are minor $(\sim 1.5 \% \mathrm{RH})$, and the panel shows no reactions, except for the $7 / 2009$ event, when $\mathrm{RH}$ increases by $\sim 3 \%$ during $\sim 15$ days and a small but significant deflection (corresponding to approximately $\varepsilon=0.02 \%$ on the back face) shows up.
} 

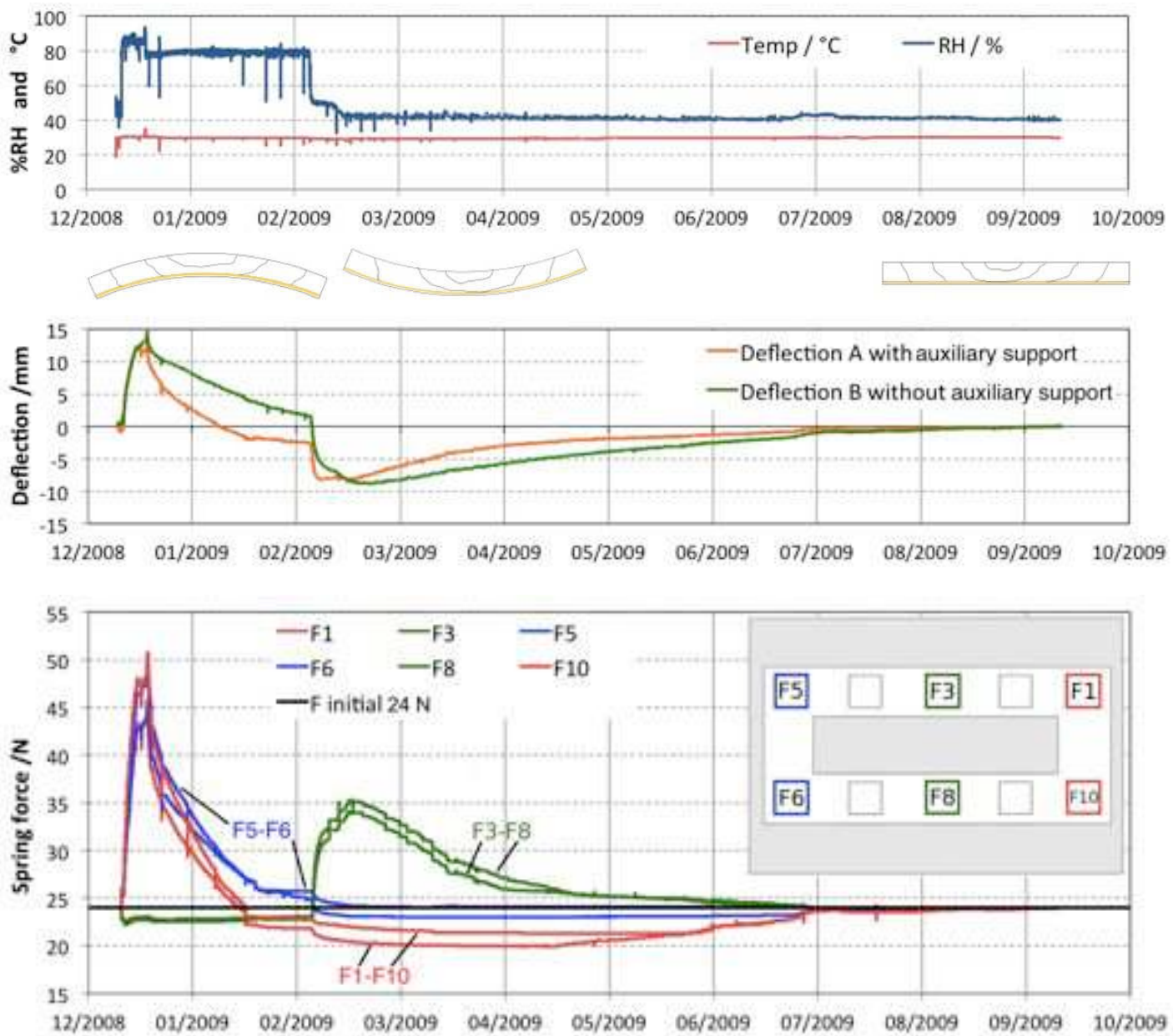

Fig. 4 - Evolution of relative humidity $(\% \mathrm{RH})$ and temperature $\left({ }^{\circ} \mathrm{C}\right)$ over time and their effect on the central deflection $(\mathrm{mm})$ and spring forces $(N)$ for replica “ $A$ " (with the auxiliary support) and replica " $B$ " (without any auxiliary support). Note: F1-F3-F5-F6-F8-F10 identify the positions of the monitored springs, on the schematic drawing of the replica " $A$ " and of the auxiliary support

Spring loading tends to keep the panel flat in case of a tendency to cup. When the bending moment generated by MC gradients acts to move away the panel from the flat state, the two effects are opposed. This affects the panel reactivity to climatic changes. As evidenced by Fig. 4b, when the cupping decreases, the panel equipped with the auxiliary support is more reactive than the one without support. The difference between " $A$ " and " $B$ " deflections, $f A=12.9 \mathrm{~mm}$ and $\mathrm{fB}=14.6 \mathrm{~mm}$ (Fig. $4 \mathrm{~b}$ ), is not very important: deflection reduction due to the use of the support is only $12 \%$. This suggests that with the present design mainly the panel, rather than the support, drives the global behaviour of the system. The forces are measured (by means of the spring deformations) at selected springs, and differ according to their positions along the width. Small differences between forces at corresponding springs (F1 and F10), (F3 and F8) and (F5 and F6), visible in Fig 4c, highlight a slightly nonsymmetric behaviour of the panel, although the difference never exceeds $2 \mathrm{~N}$, a relative difference of $4 \%$. The forces are larger when moisture increases $(51 \mathrm{~N})$ than when moisture decreases $(20 \mathrm{~N})$; this is due to different deformation dynamics produced by the asymmetry of moisture exchanges (and boundary conditions) between the panel and the environment during the transient phases (see following $\S$ $3)$. 


\section{Modelling the support action}

\subsection{Model description}

A numerical one-dimensional beam model, based on finite elements, is used to simulate the support action and the panel movements (Fig. 5). The panel movements are predicted by the model, with the assumption that the front (painted) face is totally impervious to water vapour. This reflects an ideal situation, where protective varnish is still an efficient continuous layer. That will emphasize the transient deformations caused by the presence and the evolution in time of non-symmetric moisture content. Other crude assumptions will be made, such as an equivalent stiffness for the support beams, and an assumed moisture profile along the panel thickness. The validity of these assumptions is not much an issue here. Their replacement by more realistic alternatives is always possible, without affecting the global logic of the approach (but number of input parameters has to be related to craftsmen needs).

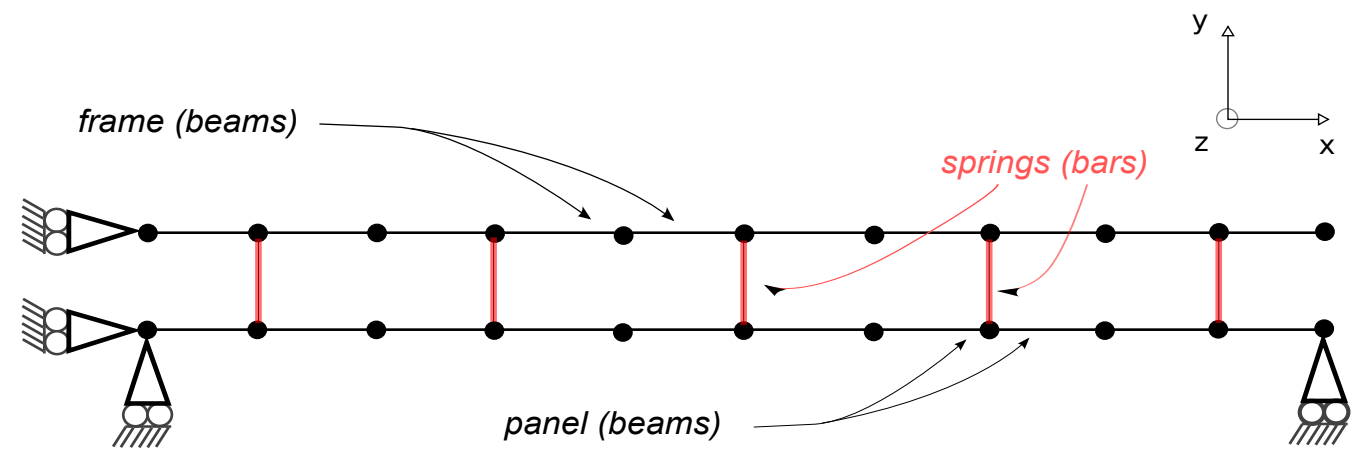

Fig. 5 - 2D finite elements model of a wooden panel, with the auxiliary support connected by means of springs

The model takes into consideration the unilateral contact conditions between the panel and the support, the stiffness of springs and their pre-load. When the contact is established (no gap) the contact force equals the initial pre-load. When the panel cups, the spring force is larger than the initial pre-load and tends to establish the contact.

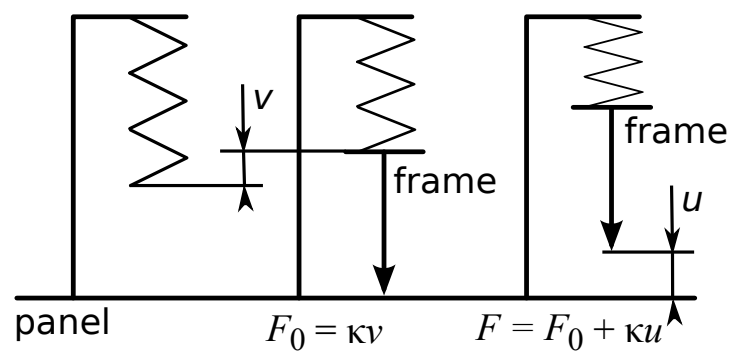

Fig. 6 - Definition of the spring force and pre-strain: (left) free mounting, (centre) pre-strain, (right) after cupping 
We assume here a linear relationship between the spring force and its compression deformation (Fig. 6); the overall behaviour can be summarized as

$$
u=\kappa^{-1}\left\langle F-F_{0}\right\rangle_{+}
$$

with $u$ the spring compression deformation due to the panel cupping and $\kappa$ the spring linear stiffness. The brackets denote the positive part of their argument. This model is implemented as a parallel association of springs and unilateral contact conditions between the support and the panel. Finally, the boundary conditions are chosen to fix the rigid body motions. The moisture content is defined as $w=\left(m_{w}-m_{o}\right) / m_{o}$ with $m_{w}$ and $m_{o}$ the sample mass in wet and oven dried condition, respectively [17]. The moisture distribution along the thickness is here assumed to be linear (Fig. 7), though experimental results of Kollmann [18] can be used as an alternative.

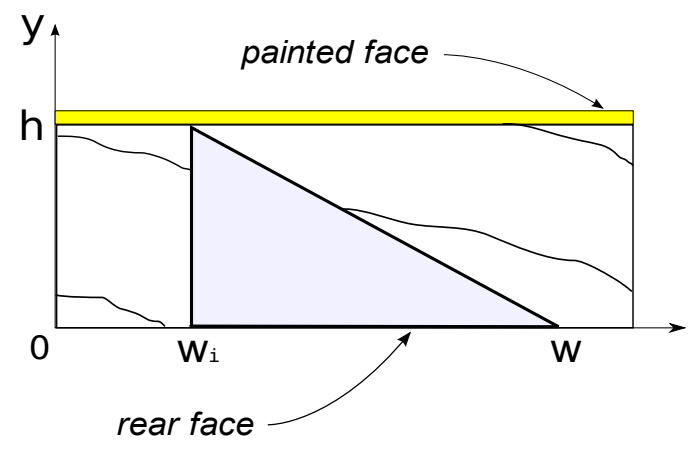

Fig. 7 - Moisture content gradient along the board thickness

This assumption on the moisture variation in the thickness can lead to an overestimation of the deflection. A linear relation between swelling/shrinkage and moisture content is assumed.

If the reference state is defined as the one with a uniform moisture content $w_{i}$ (an initial stabilized state), the constitutive equation can be written as:

$$
\sigma=E\left(\varepsilon-\varepsilon_{w}\right) \text { where } \varepsilon_{w}=\alpha\left(w-w_{i}\right)(1-y / h)
$$

where $w$ is the moisture content; $\varepsilon, \sigma, E$ and $\alpha$ are the strain, stress, Young's modulus and hygroscopic expansion along the beam length direction, respectively, and $h$ is the board thickness.

The bending moment $M$ due to the moisture content gradient along the thickness, calculated at the middle of the thickness, can be expressed as:

$$
M=b \int_{0}^{h} E \varepsilon(y)(h / 2-y) d y
$$

where $b$ is the width of the wood piece. 
So, with the previous assumptions, one gets:

$$
M=\frac{1}{12} b h^{2} E \alpha\left(w-w_{i}\right)
$$

The model is parameterized in order to highlight quantities of practical significance for designing the auxiliary support: initial compression deformation of springs $v$, springs stiffness $\kappa$, number of springs per crossbar of the support, panel width, length and thickness, wood properties of both panel and support, number of crossbars in the support (Table 1).

Table 1 - Parameters used in the model (for values with a starred superscript, refer to Annex A1)

\begin{tabular}{|c|c|c|c|c|c|}
\hline \multicolumn{2}{|c|}{ PANEL (poplar) } & \multicolumn{2}{|c|}{ SUPPORT (oak) } & \multicolumn{2}{|l|}{ SPRINGS } \\
\hline$E^{*}$ & $607 \mathrm{MPa}$ & $E$ & $14155 \mathrm{MPa}$ & $\kappa$ & 2.4 N.mm ${ }^{-1}$ \\
\hline$\alpha *$ & $0.195 \% / \%$ & $\alpha$ & $0 \% / \%$ & $v$ & $10 \mathrm{~mm}$ \\
\hline Width & $768 \mathrm{~mm}$ & Width & $768 \mathrm{~mm}$ & \# of spring per crossbars & 5 \\
\hline Height & $600 \mathrm{~mm}$ & Height & $160 \mathrm{~mm}$ & \# of crossbars & 2 \\
\hline Thickness & $38 \mathrm{~mm}$ & Thickness & $22 \mathrm{~mm}$ & & \\
\hline Weight & $8363 \mathrm{~g}$ & Weight & $3602 \mathrm{~g}$ & & \\
\hline
\end{tabular}

\subsection{Numerical results}

The simulation concerns a panel initially at a stable humidity state, which is dried by reducing the moisture content by $6.6 \%$, arising from a fall from 80 to $40 \% \mathrm{RH}$ according to the average isotherm sorption curve described by the Guggenheim, Anderson and Boer-Dent (GAB) model in Bratasz [19] for Populus sp. hardwood:

$$
w=w_{m} \frac{C_{G A B} K_{G A B} a_{0}}{\left(1-K_{G A B} a_{0}\right)\left(1-K_{G A B} a_{0}+C_{G A B} K_{G A B} a_{0}\right)}
$$

with $a_{0}=R H / 100$ the air relative humidity, $w_{m}$ the moisture content of the monolayer on dry basis, $C_{G A B}$ the energy constant related to the difference of free enthalpy of water molecules in the liquid state and in the monolayer, $K_{G A B}$ characterizing the state of the sorbed molecules beyond the first layer. The GAB constants are given in Table 2 together with other material parameters of wood extracted from Guitard [20] and Bratasz [19]. 
Table 2 - Material characteristics of poplar and oak wood determined at $13.7 \%$ of moisture content at $20^{\circ} \mathrm{C}$ and depending on the density $d$ (after [19,20]) and parameters of the GAB model

\begin{tabular}{|c|c|c|c|c|}
\hline \multicolumn{3}{|c|}{$\begin{array}{l}\text { Guitard [20] } \\
\text { Hardwood }\end{array}$} & \multicolumn{2}{|c|}{$\begin{array}{l}\text { Bratasz [19] } \\
\text { GAB model }\end{array}$} \\
\hline & Populus Alba L. & Quercus sp. & & Populus sp. at $20^{\circ} \mathrm{C}$ \\
\hline$d$ & $0.45 \pm 0.03$ & $0.65 \pm 0.03$ & $w_{m}$ & $0.06 \%$ \\
\hline$w$ & $13.7 \%$ & $13.7 \%$ & $C_{G A B}$ & 9.98 \\
\hline$\theta$ & $20^{\circ} \mathrm{C}$ & $20^{\circ} \mathrm{C}$ & $K_{G A B}$ & 0.73 \\
\hline$E_{R}$ & $1065 \pm 92 \mathrm{MPa}$ & $1718 \pm 103 \mathrm{MPa}$ & $\alpha_{R}$ & $0.12 \pm 0.03 \% / \%$ \\
\hline$E_{T}$ & $515 \pm 60 \mathrm{MPa}$ & $977 \pm 75 \mathrm{MPa}$ & $\alpha_{T}$ & $0.27 \pm 0.03 \% / \%$ \\
\hline$E_{L}$ & $9692 \pm 665 \mathrm{MPa}$ & $14155 \pm 673 \mathrm{MPa}$ & & \\
\hline
\end{tabular}

The finite element model uses $n_{s}=1005$ elements (the 2-node Hermite elements - 500 for the panel and 500 for the support, plus one 2-node bar element for each spring), all the calculations were performed using the open-source finite-element code Cast3m $[21,22]$. The model response with the previous loading is depicted in Fig. 8.

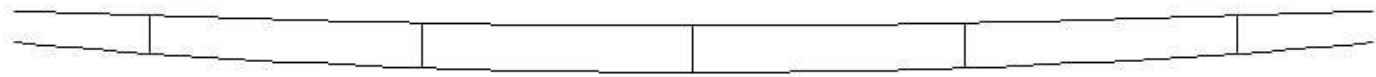

Fig. 8 - Numerical solution for a decrease by $7 \%$ in the moisture content on the panel

The maximum central deflection obtained is $23.8 \mathrm{~mm}$. The maximum force in the springs is located at the centre of the panel with a value of $102 \mathrm{~N}$. If the support did not exist, the central deflection would be $25.2 \mathrm{~mm}$, so that the deflection reduction due to the support is $6 \%$.

Table 3 - Central deflection (in $\mathrm{mm}$ ) resulting from various spring configurations

\begin{tabular}{c|cccc}
\hline \multirow{2}{*}{$v(\mathrm{~mm})$} & \multicolumn{4}{|c}{$\kappa\left(\mathrm{N} \cdot \mathrm{mm}^{-1}\right)$} \\
\cline { 2 - 5 } & $\approx 0$ & 1 & $\mathbf{2 . 4}$ & 50 \\
\hline 5 & $\mathbf{2 5 . 2}$ & 24.9 & 24.1 & 13.5 \\
$\mathbf{1 0}$ & $=$ & 24.7 & $\mathbf{2 3 . 8}$ & 11.6 \\
20 & $=$ & 24.4 & 23.0 & $=$ \\
30 & $=$ & 24.0 & 22.2 & $=$ \\
50 & $=$ & 23.3 & 20.6 & $=$ \\
\hline
\end{tabular}

Table 3 gives some results of the model in various conditions. One can notice that the spring mechanism in the support device is not very effective here. The support structure is not so stiff and the selected springs have a low stiffness. This confirms that the support structure is under-dimensioned with such geometry and mechanical properties. 


\subsection{Influence of material parameters}

Influence of moisture gradient

The analysis of a simple 1D diffusion model along the thickness was performed to check if the linear gradient assumption is acceptable, and is reported in Annex A3. The internal bending moment calculated using a more realistic, non-linear moisture gradient differs by less than $5 \%$ from that obtained using a linear gradient. Thus, the linear gradient is accepted to keep the model as simple as possible. The assumption of a perfectly impervious latex layer is less acceptable. The over-estimation of the bending moment (and of the cupping) can be estimated at $27 \%$ according to the calculations detailed in Annex A3.

Influence of the material radial orthotropic basis (related to the change of the growth rings orientation along the width)

As it is well known, the material behaviour of the wood has a radial orthotropic symmetry due to its radial secondary growth. This specificity changes the anatomical structure along the board width. The influence is discussed in Annex A1, even if the shearing effect is neglected (Colmars [4] has proposed some way for taking the shearing effect into account). As before, we focus on the effect of the material basis rotation compared to a simple model with a homogeneous radial direction along the width. This choice generates an estimated error on the central deflection of 39\%: the simulation gives a central deflection of $14.6 \mathrm{~mm}$, whereas the flatsawn orientation (see the Annex A1) gives $23.8 \mathrm{~mm}$, due to a much higher swelling expansion of wood in the tangential direction). It is important to keep in mind that the model result is dramatically influenced by the value of the swelling parameter (not determined experimentally herein) and the moisture content variation (predicted with a sorption curve, not measured herein).

\section{Influence of the latex layer}

In this simplified model, the latex (or the pictorial layer in the real case) was just considered as setting a humidity boundary condition. The mechanical role of this layer has not been taken into account. A simple estimation by homogenization, like in Marcon [5], with two layers of different bending stiffness, leads to an error in deflection of $29 \%(\psi=1.29)$ for a $2 \mathrm{~mm}$ thickness gesso layer of a stiffness of $2000 \mathrm{MPa}$ and less than $1 \%(\psi=1.002)$ for a $2 \mathrm{~mm}$ thickness of latex layer with a stiffness of $10 \mathrm{MPa}$ (the case here), see Hagan [23]. These errors are extracted from Annex A2. So the effect of a gesso layer should not be under-estimated. Nevertheless, this analysis assumes a perfect paint layer, while with ageing it exhibits many microcracks (craquelures) and its stiffness may be smaller. Cracking with a large number of micro-cracks may indeed reduce the overall macroscopic stiffness. There is locally a stress redistribution that leads to a crack network [12]. Taking into account the ageing effect, the additional stiffness is not an issue, but renders the model more difficult to manage (with the requirement for a further new constitutive parameter to be estimated). 


\subsection{Model sensitivity analysis}

To assess the accuracy of the numerical method, several spatial discretisations for the model are considered. The numerical results are reported in Fig. 9 as the evolution of the central deflection on the panel with different numbers of elements $n_{S}$. The solution converges quickly with more than $n_{S}=100$ elements, with a relative error of $0.03 \%$ on the central deflection, and for $n_{S}=500$ the total convergence is reached. This last value was selected in all simulations in this study.

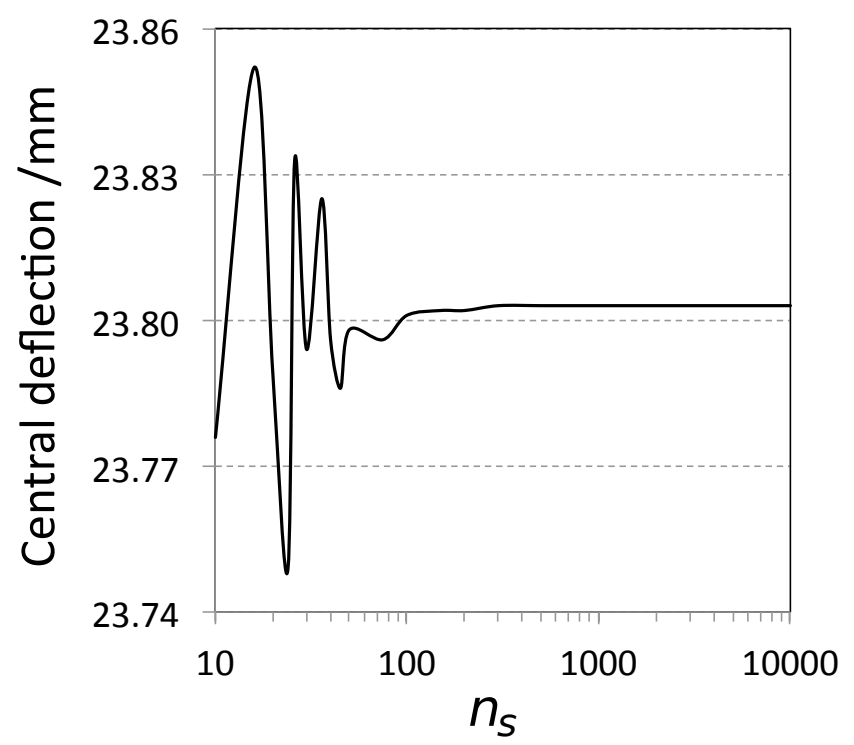

Fig. 9 - Influence of the discretisation - the number of elements $n_{s}$ - on the central deflection.

The sensitivity of the model's response to variations in the material parameters was also tested. Each parameter $x$ was increased or decreased by its respective error $\Delta x$ determined in Table 2 and the influence on the central deflection and the maximum spring force is summarised in Table 4 (for $\beta=1.1$, see Annex A3). The complete analysis indicates that the swelling/shrinkage parameter mainly drives the model response. Next sections compare the experimental and the numerical results.

Table 4 - Model sensitivity to input parameters

\begin{tabular}{ccccc}
\hline & $E^{*}(\mathrm{MPa})$ & $\alpha^{*}$ & $f(\mathrm{~mm})$ & $F(\mathrm{~N})$ \\
\hline$\underline{x}-\Delta x$ & 540 & 0.165 & 14.4 & 79 \\
$\underline{\boldsymbol{x}}$ & $\mathbf{6 0 7}$ & $\mathbf{0 . 1 9 5}$ & $\mathbf{1 7 . 2}$ & $\mathbf{8 6}$ \\
$\underline{x}+\Delta x$ & 678 & 0.225 & 20.1 & 93 \\
\hline
\end{tabular}

* for values with a starred superscript, refer to Annex A1 


\subsection{Comparison between experimental and numerical results}

The numerical study has taken into account the growth ring orientation, impermeability of the latex layer to water vapour as described in the previous sections. Table 5 summarizes the results in terms of the central deflection and the maximum force applied by springs. The numerical model overestimates the spring forces as well as the central deflection. The indicated error ranges are deduced from the sensitivity analysis for the numerical model, and from the sensor precisions for the experimental measurements. For practical purpose of this model, we choose to provide a framework for which only input parameters from literature are required, and not parameters measured for the replica. In such a case, a predictive accuracy of about $33 \%$ is reached (with the measured input parameters, the accuracy can be improved with the same model). Nevertheless, this accuracy is sufficient considering the purpose of such model.

Table 5 - Comparison between experimental and numerical results for the support effect on the panel central deflection and forces applied by the springs

\begin{tabular}{|l|c|c|c|c|}
\cline { 2 - 5 } \multicolumn{1}{c|}{} & $\begin{array}{c}F_{\max }(\mathrm{N}) \\
\text { spring }\end{array}$ & $\begin{array}{c}f_{\max }(\mathrm{mm}): \\
\text { with the } \\
\text { support (A) }\end{array}$ & $\begin{array}{c}f_{\max }(\mathrm{mm}): \\
\text { without any } \\
\text { support (B) }\end{array}$ & $\begin{array}{c}\text { Effect of the } \\
\text { support on the } \\
\text { deflection } \\
\text { reduction }\end{array}$ \\
\hline Humidity step & $51 \pm 2$ & $12.9 \pm 0.8$ & $14.6 \pm 0.9$ & $12 \%$ \\
\hline Experimental & $86 \pm 7$ & $17.2 \pm 2.9$ & $18.4 \pm 2.8$ & $7 \%$ \\
\hline Numerical & $68 \%$ & $33 \%$ & $26 \%$ & \multicolumn{1}{c|}{} \\
\hline Error num/exp & \multicolumn{4}{|c|}{$\Delta \mathrm{RH}=+40 \%$ or $\Delta w=+6.6 \%$} \\
\hline
\end{tabular}

The model can now be used to provide a tool for restorers to determine optimised support dimension and spring adjustment in relation to the deflection reduction that is expected, together with a limitation of forces that the springs exert on the board.

\section{Global behaviour design diagram}

The aim here is to provide restorers with a tool which may assist them to design and adjust the auxiliary support and the springs. Following discussions with several restorers, three elements have been identified which need to be taken into account for the device optimisation: (1) the rupture force of the connection between the panel and the support (usually glued); (2) the total stress level, induced by springs on the panel, not to be exceeded; (3) the deflection reduction one expects to obtain. The two main adjusting variables are on the one hand the spring stiffness and pre-load, and on the other hand the global structural stiffness of the support, controlled by Young's modulus and thickness of the cross beams. According to the assumptions made in this study and the chosen model, one can anticipate that: (i) the Young's modulus of the support has a first-order effect on its structural stiffness; (ii) the thickness contributes by an order 3 to the bending inertia (and hence to the structural stiffness) but by an order 1 to the deflection due to humidity fluctuations; (iii) the ratio of support and 
panel widths contributes by an order 1; (iv) increasing the number of springs lines is equivalent to increasing the spring stiffness.

This analysis allows to conclude that the three following parameters mainly control the global behaviour of the support+panel system: the spring stiffness $\kappa\left(\mathrm{N} . \mathrm{mm}^{-1}\right)$, the spring pre-load deflection $v(\mathrm{~mm})$ and the thickness of the support $h(\mathrm{~mm})$. Once the basic variables of the problem are identified, one may study their influence by scanning their admissible ranges of variation. For instance, the springs available and the preload deformation determine that their stiffness can range between almost zero to $80 \mathrm{~N} . \mathrm{mm}-1$ and a preload $v$ from 0 to $10 \mathrm{~mm}$. Table 6 gives all the parameters of the simulation.

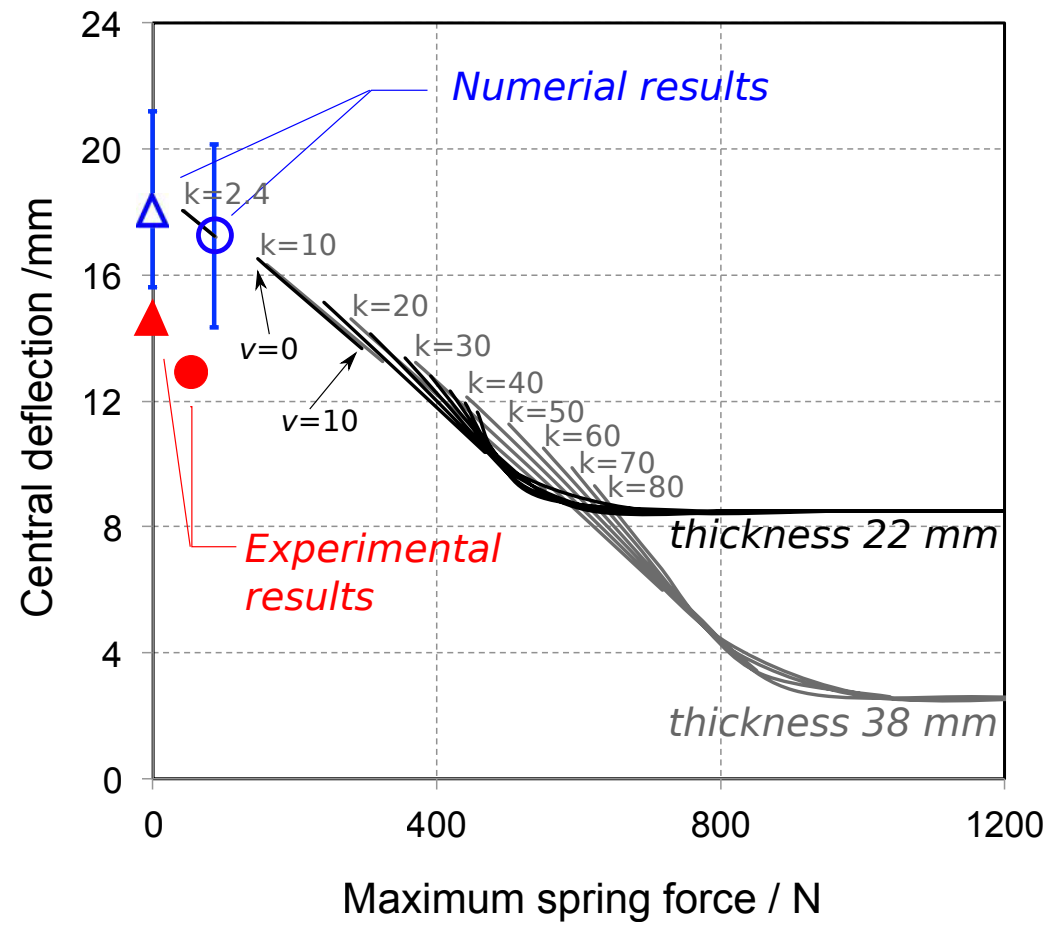

Fig. 10 - Design diagram of the auxiliary support for two thicknesses of its cross-beams: 22 and 38 mm. $\kappa$ : linear stiffness of springs $\left(\mathrm{N} . \mathrm{mm}^{-1}\right)$, v: preload deflection of springs (mm). Caption: the triangles $(\Delta)$ stand for results without support and the circles $(O)$ stand for results with support.

Table 6 - Parameters used for the thickness effect study, in order to plot Fig. 10

\begin{tabular}{ll|ll|ll}
\hline \multicolumn{2}{l|l}{ PANEL (poplar) } & \multicolumn{3}{l}{ SUPPORT (oak) } & SPRINGS \\
\hline$E^{*}$ & $607 \mathrm{MPa}$ & $E$ & $14155 \mathrm{MPa}$ & $\kappa$ & 0 to 80 N.mm \\
$\alpha *$ & $0.195 \% / \%$ & $\alpha$ & $0 \% / \%$ & $v$ & 0 to $10 \mathrm{~mm}$ \\
Width & $768 \mathrm{~mm}$ & Width & $768 \mathrm{~mm}$ & \# of spring per crossbars & 5 \\
Height & $600 \mathrm{~mm}$ & Height & $160 \mathrm{~mm}$ & \# of crossbars & 2 \\
Thickness & $38 \mathrm{~mm}$ & Thickness & 22 and $38 \mathrm{~mm}$ & & \\
\hline
\end{tabular}

Fig. 10 shows the maximum deflection at the centre of the panel with respect to the force applied by the springs for a decrease by $6.6 \%$ in the moisture content, for different pairs of stiffness and initial spring loading deformation $(\kappa, v)$. It highlights the fact that the support as initially proposed by the restorer ( $22 \mathrm{~mm}$ thick) is underdimensioned. Indeed, whatever the spring stiffness/preload $(\kappa, v)$, one can expect a $54 \%$ reduction of the central deflection of the panel. The initial design of the support 
is too compliant, so in Fig. 10 it is compared with a case of a support thickness equivalent to that of the panel $(38 \mathrm{~mm})$. This thickness allows a wider range of deflection reduction. The restorer is hence to choose the best compromise between an optimal deflection reduction (to avoid negative aesthetic effect and to control strain in the pictorial layer [12]) and the loads applied on the panel. This diagram provides only two configurations of thickness; obviously the finite element model can provide curves for other ranges of thickness.

\section{Conclusion}

An actual conservation treatment has been studied, by which an ad hoc auxiliary support was designed to partially control the wooden support's deformations under humidity variations. A numerical model is provided and used to generate a design diagram. The model was verified experimentally on a replica of the original panel painting.

On the one hand, numerical results and experimental measurements obtained indicate that the auxiliary support which has been used in the experimental tests should have been stiffer, in order to be efficient. With the present configuration, the maximum effect (with stiff springs and a large pre-load) is a reduction of $12 \%$ of the deflection. With a stiffer frame, a higher influence of the support can be expected. A study of forces and stresses in the panel has to be carried out to get more relevant answers. The numerical model gives results with an accuracy of about $33 \%$ when compared to the experiments, in the present case of a latex coating.

Simplistic assumptions were made to reduce as much as possible the parameters (estimated here from the literature data) of the model. Some phenomena are not taken into account here: the deformation produced by shear in a bending test (see Colmars [4]), the coupling between the moisture diffusion and the elastic behaviour (see Dureisseix [12,6]), the mechano-sorptive effects [4-6,17,24,25]. Other authors have conducted research on bending due to wood drying, e.g. Mauget [26], Olek [27,28], Perré [29] and Rémond [30] to calculate curvature and stresses (2D and 3D).

The study shows that sufficient information about the wood structure controlling the swelling behaviour can be obtained from simple direct observation of the edge of the panel.

The experimental study is still in progress. This article focuses on only one complete cycle of moistening-drying (40-80-40\%RH) lasting almost one year, because the panel requires 5 months to reach a steady state. By integrating all the subsequent data, we expect to characterize more precisely the behaviour of the support combination in a further study.

However, balance must be found between the model's accuracy, and availability of the required input data and ease of use.

Finally, as already mentioned in the Introduction, choosing the type and amount of desirable control, to obtain the best possible conservation of the painting is a fundamental choice, to be made on the basis of the conservation problems shown by the painted panel, and of the expected environmental conditions. Such subject needs further research and discussion with curators and restorers, so that they are provided with further suitable decision-making tools, in addition to their wide knowledge

\section{Acknowledgements}

The Authors wish to thank Daniele Piacenti, an independent Florentine restorer; Marco Ciatti and Ciro Castelli, Opificio delle Pietre Dure; Daniel Jaunard and Patrick 
Mandron, two French restorers, for their help and fruitful discussions. The first author acknowledges funding from CNRS, Région Languedoc-Roussillon and from the Vinci 2007 programme (Université Franco-Italienne). The participation of one master student, Damiano Zazzeri, was important to complete this study.

\section{References}

[1] R.D. Buck, The use of moisture barriers on panel paintings, Studies in Conservation 6(1) (1961) 9-20.

[2] D. Dureisseix, J. Colmars, A. Baldit, F. Morestin, H. Maigre, Follow-up of a panel restoration procedure through image correlation and finite element modelling. International Journal of Solids and Structures 48(3) (2011) 10241033.

[3] J. Colmars, Hygromécanique du materiau bois appliquée à la conservation du pratrimoine culturel : étude sur la courbure des panneux peints, $\mathrm{PhD}$ thesis, University of Montpellier 2, France (2011).

[4] B. Marcon, D. Dureisseix, D. Jullien, L. Uzielli, J. Gril, Hygromechanical study of painted panels, Proceedings of COST Action IE0601, Tervuren, Belgium (2007).

[5] B. Marcon B, Hygromécanique des panneaux en bois et conservation du patrimoine culturel: des pathologies... aux outils pour la conservation, $\mathrm{PhD}$ thesis, University of Montpellier 2, France (2009).

[6] P. Mazzanti, M. Togni, L. Uzielli, Drying shrinkage and mechanical properties of poplar wood (Populus alba L.) across the grain. J. of Cult. Her., Special issue on Wood science and conservation (2012).

[7] M.F. Mecklenburg, C.S. Tumosa, D. Erhardt, Structural response of painted wood surfaces to changes in ambient relative humidity, Getty Conservation Inst. (1998) 464-483.

[8] M. Ciatti, C. Castelli, A. Santacesaria, Dipinti su tavola, la tecnica e la conservazione dei supporti, Edifir Firenze (1999)188-192.

[9] L. Uzielli, O. Casazza, Conservazione dei dipinti su tavola, Nardini Editore, Arte e Restauro (1992) 47-72.

[10]M. Miller, G. Bisacca, D. Galitzine, The development of a spring mechanism for the use in conjunction with auxiliary supports for previously thinned panels, in: Phenix, Alan and Sue Ann Chui, (Eds.). Proceedings of the Getty Conservation Institute, Los Angeles, USA (2011) 59-68.

[11]C. Cennini, Il Libro dell'arte, traité des arts, L'œil d'or Ed., (1437) 192.

[12]D. Dureisseix, B. Marcon, A partitioning strategy for the coupled hygromechanical analysis with application to wood structures of cultural heritage, Int. J. of Num. Meth in Eng. 88(3) (2011) 228-256.

[13]P. Dionisi Vici, P. Mazzanti, L. Uzielli, Mechanical response of wooden boards subjected to humidity step variations: climatic chamber measurements and fitted mathematical models, J. of Cult. Her. 7(3) (2006) 37-48.

[14]L. Uzielli, P. Dionisi Vici, J. Gril (2006); Physical and mechanical characterization of the support, in: J.P. Mohen, M. Menu, B. Mottin, Mona Lisa, inside the painting. Abrams, New York, United States (2006) chapter II.4.

[15]L. Uzielli, P. Dionisi Vici, J. Colmars, Instrumentation pour le contrôle continu des panneaux peints en bois, Techné 29 (2009) 21-27.

[16] L. Uzielli, L. Cocchi, P. Mazzanti, M. Togni, D. Jullien, P. Dionisi-Vici, The Deformometric Kit: a method and an apparatus for monitoring the deformation of 
wooden panels, J. of Cult. Her., Special issue on Wood science and conservation (2012).

[17]Z.P. Bazant, Constitutive equation of wood at variable humidity and temperature, Wood science and Technology 19 (1985) 159-177.

[18]F.P. Kollmann, W.A. Côté, Principles of Wood Science and Technology, Springer Verlag (1968) 185-186.

[19]L. Bratasz, R. Kozlowski, B. Rachwa, Sorption of moisture and dimensional change of wood species used in historic objects, Proceedings of COST Action IE0601, Braga, Portugal (2008) 15-20.

[20]D. Guitard, Mécanique du Matériau Bois et Composites, Cepadues Editions, Toulouse, France (1987).

[21]P. Verpeaux, T. Charras, A. Millard, CASTEM $2000:$ une approche moderne du calcul des structures, Calcul des Structures et Intelligence Artificielle, J.M. Fouet, P. Ladevèze, R. Ohayon Eds. 2, Paris, France (1998) 261-271.

[22]P. Verpeaux, A. Millard, T. Charras, A. Combescure, A modern approach of large computer codes for structural analysis, Proceedings of 10th International Conference on Structural Mechanics in Reactor Technology (1989).

[23]E.W. Hagan, M.N. Charalambides, C.R. Young, T.J. Learner, S. Hackney, Viscoelastic properties of latex paint films in tension: Influence of the inorganic phase and surfactants, Progress in Organic Coatings 69 (2010) 73-81.

[24]A. Ranta-Maunus, The viscoelasticity of wood at varying moisture content, Wood Science and Technology 9 (1975) 189-205.

[25]J.G. Salin, Numerical prediction of checking during timber drying and a new mechano-sorptive creep model, Holz als Roh-und Werkstoff 50 (1992).

[26]B. Mauget, Simulation en grands déplacements du comportement mécanique du bois - Application au séchage dissymétrique et séchage sous charge, $\mathrm{PhD}$ thesis, Institut National Polytechnique de Lorraine, France (1996).

[27]W. Olek, J. Weres, Effects of the method of identification of the diffusion coefficient on accuracy of modeling bound water transfer in wood, Transport in Porous Media 66 (2007) 135-144.

[28] W. Olek, P. Perré, J. Weres, Inverse analysis of the transient bound water diffusion in wood, Holzforschung 59 (2005) 38-45.

[29] P. Perré, I. Turner, A 3-D version of TransPore: a comprehensive heat and mass transfer computational model for simulating the drying of porous media, International Journal of Heat and Mass Transfer 42 (1999) 4501-4521.

[30]R. Remond, J. Passard, P. Perré, The effect of temperature and moisture content on the mechanical behaviour of wood: a comprehensive model applied to drying and bending, European Journal of Mechanics and Solids 26 (2007) 558-572.

[31]E.T. Engelund, L. Ulriksen, K.K. Hansen, T. Astrup, P.H. Meyer, The influence of moisture content on the water vapour resistance of surface coated spruce. Proceedings of the 7th Symposium on Building Physics in the Nordic Countries 1, Reykjavik, Iceland (2005) 188-194.

[32]R.J. Gettens, G.L. Stout, Painting materials, a short encyclopedia, Dover Publications, 2nd edition, New York, USA (1996).

[33]O. Allegretti, F. Rafaelli, Barrier effect to water vapour of early European painting materials on wood panels, Studies in Conservation 53(3) (2008) 187197. 


\title{
Supplementary material of Mechanical study of a support system for cupping control of panel paintings combining crossbars and springs
}

\author{
B. Marcon, et al. Journal of Cultural Heritage (2012) \\ doi:10.1016/j.culher.2012.04.003
}

\section{A.1 Influence of the material symmetry basis (related to growth rings)}

Due to the mainly radial secondary growth of trees, the material local basis (R: radial, $\mathrm{T}$ : tangential, and L: longitudinal) changes in the wood panel. With a beam model, we try to take into account this change only in the beam axis direction, neglecting the basis change in the thickness of the panel. For instance, for the present replica with two planks, the trunk axis locations have been identified in Fig. A1 from ring orientations.

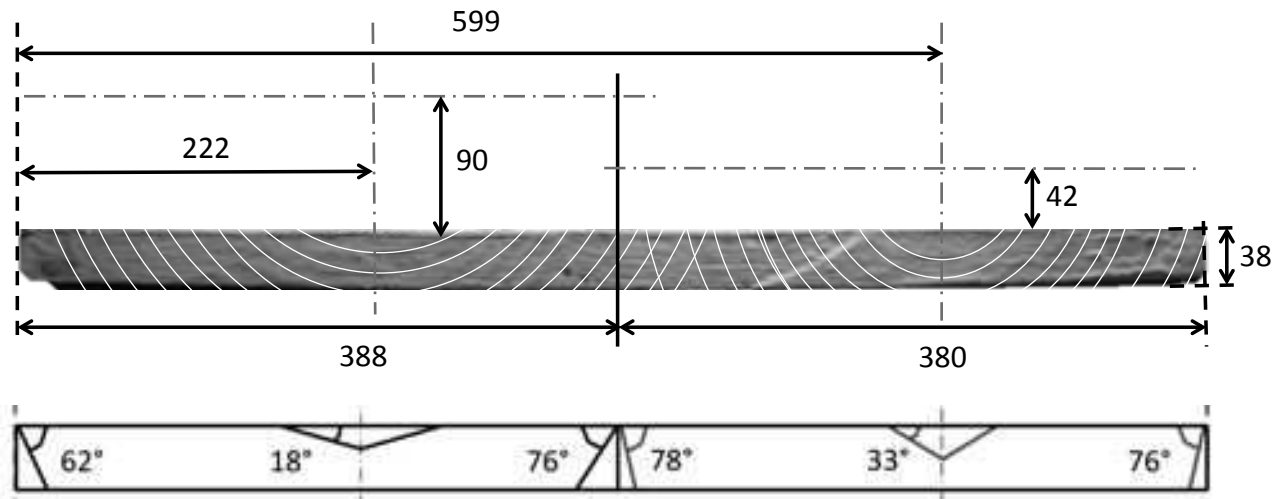

Fig. A1. Local material basis orientation for the replica (dimensions in mm).

On a single plank, assumed to be centred with respect to the axis, Fig. A2 depicts the corresponding orientation, with two dimensional parameters, $a$ and $b$. With an orthotropic material behaviour, the local axial elastic modulus $E(\mathrm{q})$ can be expressed as

$$
\frac{1}{E(\theta)}=\frac{1}{E_{T}} \cos ^{4} \theta+\frac{1}{E_{R}} \sin ^{4} \theta+\left(\frac{1}{G_{R T}}-2 \frac{v_{R T}}{E_{R}}\right) \sin ^{2} \theta \cos ^{2} \theta
$$

and its average value $E^{*}$ is such that $\frac{1}{E^{*}}=\frac{1}{b} \int_{0}^{b} \frac{1}{E(\theta)} d x$

$$
\frac{1}{E^{*}}=\frac{1}{E_{T}} \frac{1}{2}\left(\lambda+\cos ^{2} \theta_{b}\right)+\frac{1}{E_{R}}\left(1-\frac{3}{2} \lambda+\frac{1}{2} \cos ^{2} \theta_{b}\right)+\left(\frac{1}{G_{R T}}-2 \frac{v_{R T}}{E_{R}}\right) \frac{1}{2}\left(\lambda-\cos ^{2} \theta_{b}\right)
$$

with $\lambda=\theta_{b} / \tan \theta_{b}$ and $\tan \theta_{b}=b / a$. Similar expressions can be obtained for other material parameters. For instance, with the swelling / shrinkage parameters a, useful for deriving internal axial stresses, one gets

$$
\alpha^{*}=\frac{1}{b} \int_{0}^{b}\left(\alpha_{R} \sin ^{2} \theta+\alpha_{T} \cos ^{2} \theta\right) d x=\lambda \alpha_{T}+(1-\lambda) \alpha_{R}
$$


Similarly for the diffusion in the thickness direction, one gets

$$
D^{*}=\frac{1}{b} \int_{0}^{b}\left(D_{R} \cos ^{2} \theta+D_{T} \sin ^{2} \theta\right) d x=\lambda D_{R}+(1-\lambda) D_{T}
$$

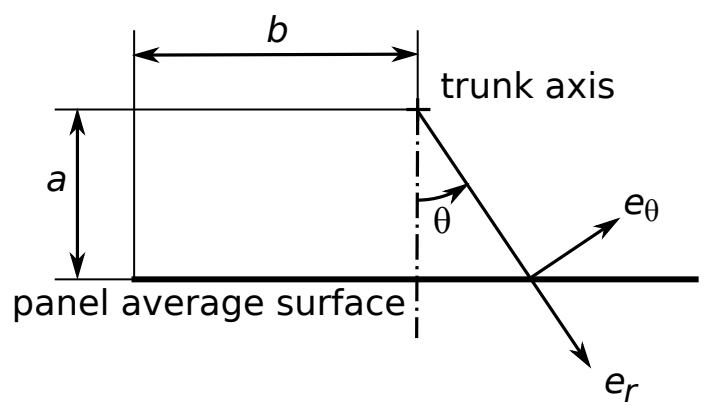

Fig. A2. Local material basis orientation model.

Since the panel is made of two planks, the averaging process can be done twice. The resulting values are collected in Table A1.

Table A1: Parameters of the panel (with data after $[12,19,20,27,28]$ ).

\begin{tabular}{llll}
\hline Planck 1 & $a=109 \mathrm{~mm}$ & $b=194 \mathrm{~mm}$ & $h=38 \mathrm{~mm}$ \\
\hline & $E_{R}=1065 \mathrm{MPa}$ & $E_{T}=515 \mathrm{MPa}$ & $E^{*}=570 \mathrm{MPa}$ \\
& $\mathrm{a}_{R}=0.12$ & $\mathrm{a}_{T}=0.27$ & $\mathrm{a}^{*}=0.209$ \\
& $D_{R}=2.50 \mathrm{e}^{-10} \mathrm{~m}^{2} \mathrm{~s}^{-1}$ & $D_{T}=0.54 \mathrm{e}^{-10} \mathrm{~m}^{2} \mathrm{~s}^{-1}$ & $D^{*}=1.71 \mathrm{e}^{-10} \mathrm{~m}^{2} \mathrm{~s}^{-1}$ \\
\hline Planck 2 & $a=61 \mathrm{~mm}$ & $b=190 \mathrm{~mm}$ & $h=38 \mathrm{~mm}$ \\
\hline & $E_{R}=1065 \mathrm{MPa}$ & $E_{T}=515 \mathrm{MPa}$ & $E^{*}=651 \mathrm{MPa}$ \\
& $\mathrm{a}_{R}=0.12$ & $\mathrm{a}_{T}=0.27$ & $\mathrm{a}^{*}=0.176$ \\
& $D_{R}=2.5010^{-10} \mathrm{~m}^{2} \mathrm{~s}^{-1}$ & $D_{T}=0.5410^{-10} \mathrm{~m}^{2} \mathrm{~s}^{-1}$ & $D^{*}=1.3310^{-10} \mathrm{~m}^{2} \mathrm{~s}^{-1}$ \\
\hline Panel & & & \\
\hline & $E^{*}=607 \mathrm{MPa}$ & $\mathrm{a}^{*}=0.195$ & $D^{*}=1.5310^{-10} \mathrm{~m}^{2} \mathrm{~s}^{-1}$
\end{tabular}

Thus, planks are described by only one Young's modulus, one swelling coefficient and one parameter for the diffusion. This additional assumption allows keeping a low number of input parameters.

\section{A.2 Influence of the gesso stiffness}

If we consider a pure bending case, with a 2-layered beam (a wood panel of thickness $h$ and stiffness $E$, and a gesso of thickness $h^{\prime}$ and stiffness $E$ '), the axial strain in the beam is $\varepsilon=\gamma(y-e)$, with $e$ the position of the neutral axis, and $\mathrm{g}$ the unitary rotation angle, Fig. A3.

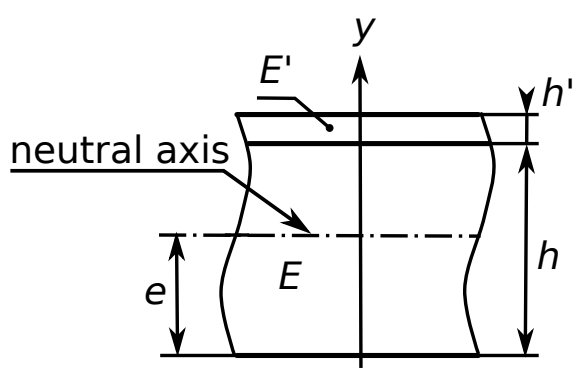

Fig. A3. A two-layered beam 
The classical beam theory leads to the expression of the neutral axis and of the bending stiffness $M / g$ ( $M$ is the bending moment). When the ratio $h / h$ is small, they read:

$\frac{e}{h}=\frac{1}{2}(1+\delta)$ with $\delta=\frac{\left(E^{\prime} h^{\prime}\right) /(E h)}{1+\left(E^{\prime} h^{\prime} / E h\right)}$, and $\frac{M}{\gamma}=\frac{E h^{3}}{12} \psi$ with $\psi=1+3 \delta$

Without gesso $\left(h^{\prime}=0\right)$, one recovers $e=h / 2$ and $\mathrm{y}=1$.

\section{A.3 Influence of the moisture content profile in the panel thickness}

The distribution of the moisture content $w$ in the panel thickness may influence the panel bending, since the corresponding internal bending moment is

$M=\int_{0}^{h} \sigma(y) \cdot(h / 2-y) d y \quad$ with $\quad \sigma=E \alpha\left[w(y)-w_{i}\right]$

A linear evolution $w=w_{i}+\Delta w(1-y / h)$ leads to an adimensional bending moment

$\bar{M}=M /\left(E \alpha \Delta w h^{2}\right)=1 / 12$

Nevertheless, one may expect the moisture content profile to be driven with moisture diffusion in the panel thickness direction, which reads:

$$
\frac{\partial w}{\partial t}=D \frac{\partial^{2} w}{\partial y^{2}}
$$

with initial conditions $w(y, t=0)=w_{i}$ and with boundary conditions $w(y=0, t)=w_{i}+\Delta w$ and, if the pictorial layer is impervious, $\rho_{o} D \partial w / \partial y=0$ at $y=h$. The adimensional version of (a8) is

$$
\frac{\partial \bar{w}}{\partial \bar{t}}=\frac{\partial^{2} \bar{w}}{\partial \bar{y}^{2}} \text { with } \bar{w}(\bar{y}, \bar{t}=0)=0, \bar{w}(\bar{y}=0, \bar{t})=1 \text { and } \frac{\partial \bar{w}}{\partial \bar{y}}(\bar{y}=1, \bar{t})=0
$$

where $\bar{w}=\left(w-w_{i}\right) / \Delta w, \bar{y}=y / h$ and $\bar{t}=t / \tau$ with the characteristic diffusion time $\tau=h^{2} / D$. The solution $\bar{w}$ can be obtained, for example numerically, and is depicted in Fig. A4a. At each time step $\bar{t}$, the adimensional bending moment $\bar{M}(\bar{t})$ can be obtained and its evolution is plotted in Fig. A4b. Its maximal value $\bar{M}_{\max } \approx 0.96 / 12$ is reached at $\bar{t}=0.084$ and is very close to the value obtained with a linear profile. Therefore, there is only a small influence of the moisture content profile for such a case. 

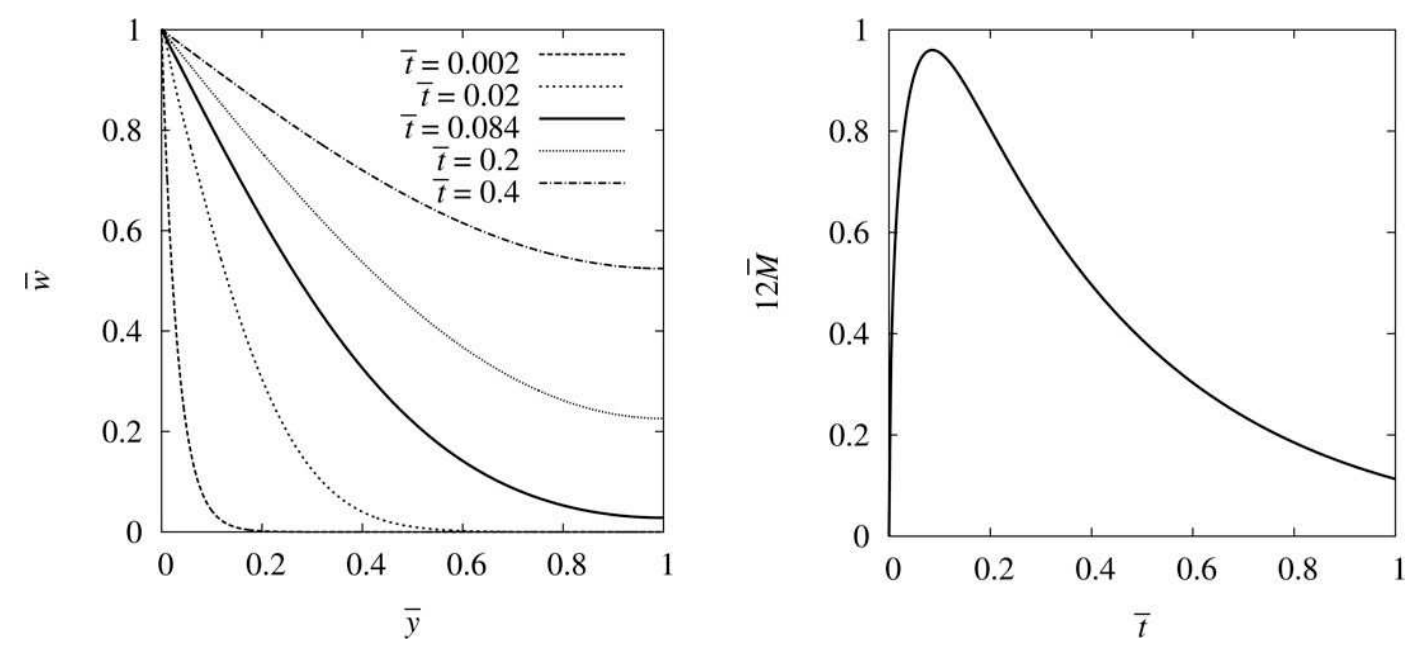

Fig. A4. (a) Moisture content profile and (b) corresponding internal bending moment.

Nevertheless, it happens that the paint layer is not perfectly impervious but exhibits a (small) moisture permeability $k$; in such a case, the boundary condition at $y=h$ is replaced with $\rho_{o} D \partial w / \partial y=-\rho_{o} k\left(w-w_{i}-\Delta w\right)$ or with the adimensional form

$$
\frac{\partial \bar{w}}{\partial \bar{y}}(\bar{y}=1)=-\beta(\bar{w}(\bar{y}=1)-1) \quad \text { with } \quad \beta=\rho_{o} k h / \rho_{o} D
$$

The previous problem to determine the moisture content profile is therefore now parameterized with $b$ and its maximal value is plotted in Fig. A5.

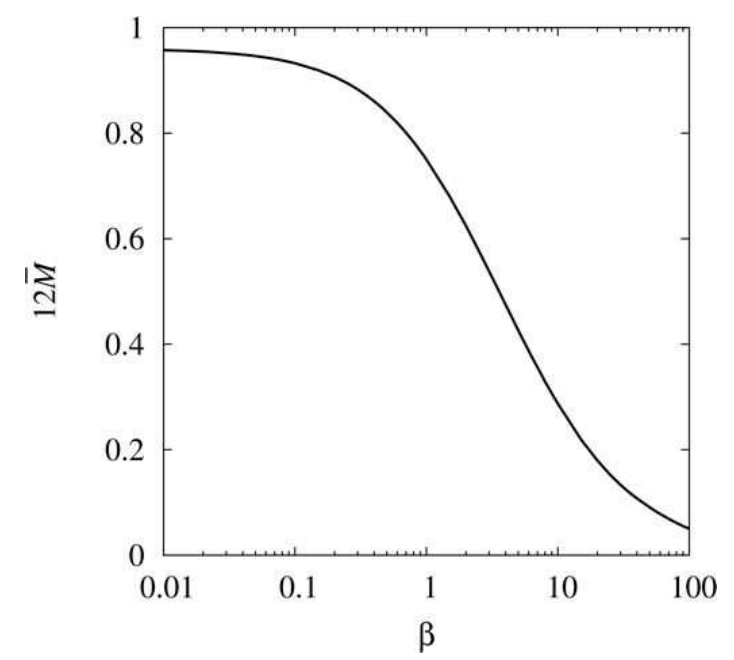

Fig. A5. Maximal internal bending moment as a function of the layer permeability.

To get a practical value for $b$, an identification of the moisture permeability $r_{o} k$ is necessary. Using literature values [31], and in [32], for spruce (Picea abies) and a water-based white acrylic paint $\left(60 \mathrm{~g} / \mathrm{cm}^{2}\right)$, the moisture permeability is $r_{o} k=8.810^{-6}$ $\mathrm{kg} \cdot \mathrm{m}^{-2} \mathrm{~s}^{-1}$. [23] reports for a cellulose acetate coating with a thickness of $0.5 \mathrm{~mm}$, an approximated value of $1.710^{-7} \mathrm{~kg} \cdot \mathrm{m}^{-2} \mathrm{~s}^{-1}$. Several typical painted layer replicas have been tested in [33] for which the values of $r_{o} k$ range between $1.610^{-6} \mathrm{~kg} \cdot \mathrm{m}^{-2} \mathrm{~s}^{-1}$ and $8.010^{-5} \mathrm{~kg} \cdot \mathrm{m}^{-2} \mathrm{~s}^{-1}$. 
The test to identify the moisture permeability of the latex layer on the replica is performed as in the following. A parallelepipedal specimen of wood is submitted to a cycle of adsorption / desorption in a climatic chamber and its mass is measured regularly. The same specimen is then entirely covered by the same latex layer as for the replica, and the same experiment is repeated. Results on relative mass variations $m(t) / m_{i}$, with $m_{i}=m(t=0)$ are depicted on Fig. A6.

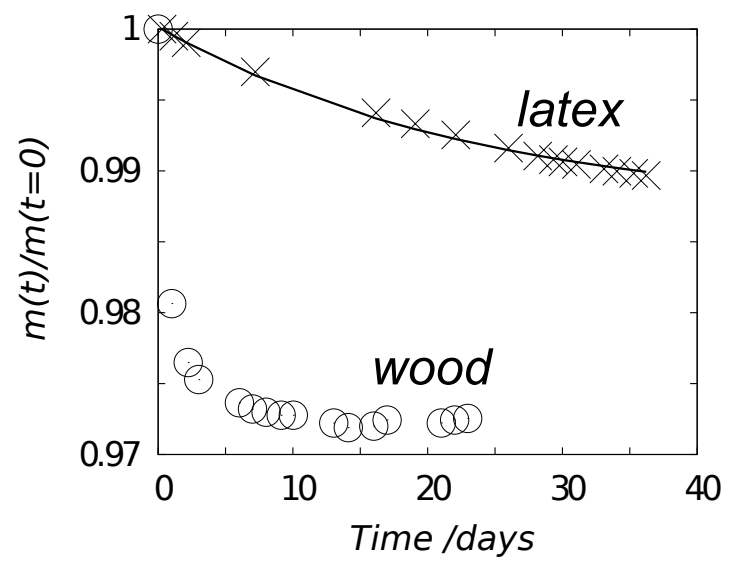

Fig. A6. Normalised mass loss during drying test from $5 \% \mathrm{RH}$ to $45 \% \mathrm{RH}$ of a bare poplar piece and a latex-coated poplar piece.

Note that both evolutions should have the same asymptote $m=m_{\infty}$ for long times. Since the moisture content in the first test (wood only) evolves much more rapidly, we can assume that for the second test, the moisture content in the specimen is uniform, while there is a jump through the latex layer. Taking the integral of the equation (a8) (in the whole specimen volume) leads to

$\int_{\Omega} \rho_{o} \frac{\partial w}{\partial t} d \Omega=\int_{\Omega} \rho_{o} D \frac{\partial^{2} w}{\partial y^{2}} d \Omega=\oint_{\partial \Omega} \rho_{o} D \frac{\partial w}{\partial y} d S=-\oint_{\partial \Omega} \rho_{o} k\left(w-w_{i}-\Delta w\right) d S$

and with the previous assumption, together with $w=\left(m-m_{o}\right) / m_{o}$ (and $m_{o}=r_{o} V$ is the oven-dry mass of the specimen, $V=80 \times 53 \times 55 \mathrm{~mm}^{3}$ being its volume and $S$ its external surface) one gets

$\frac{d m}{d t}=\frac{1}{\tau^{\prime}}\left(m_{\infty}-m\right)$ with $\tau^{\prime}=\frac{m_{o}}{\rho_{o} k S}=\frac{V}{k S}$ and $m_{\infty}=m_{i}+m_{o} \Delta w$

whose solution is

$m(t) / m_{i}=\left(m_{\infty} / m_{i}-1\right)\left(1-e^{-t / \tau^{\prime}}\right)+1$

Identifying the layer characteristic time t' from the experiment leads to $t^{\prime}=1.4$ hour and $r_{o} k=210^{-6} \mathrm{~kg} \cdot \mathrm{m}^{-2} \mathrm{~s}^{-1}$. This leads to $b=1.10$ and, from Fig. A5, a corresponding value of $12 \bar{M} \approx 0.73$ that indicates that the bending moment is over-estimated by $27 \%$ when considering the latex as perfectly impervious. 